\title{
Bacillus thuringiensis: applications in agriculture and insect resistance management. A review
}

\author{
Vincent SANCHIS $^{1 *}$, Denis BoURGUET ${ }^{2}$ \\ ${ }^{1}$ Unité de Génétique Microbienne et Environnement, INRA La Minière, 78285 Guyancourt Cedex, France \\ ${ }^{2}$ Centre de Biologie et de Gestion des Populations, UMR INRA-IRD-Montpellier SupAgro-CIRAD, Campus International de Baillarguet, 34988 Montferrier \\ sur Lez, France
}

(Accepted 22 November 2007)

\begin{abstract}
Bacillus thuringiensis (Bt) is a sporulating, Gram-positive facultative-aerobic soil bacterium. Its principal characteristic is the synthesis, during sporulation, of a crystalline inclusion containing proteins known as $\delta$-endotoxins or Cry proteins. These proteins have insecticidal properties. The considerable diversity of these toxins, their efficacy and their relatively cheap production have made $B t$ the most widely used biopesticide in the world. It is used in the fight against many agricultural crop pests - mostly lepidopteran and coleopteran larvae - notably in the creation of new plant varieties expressing Bt cry genes. For human health, Bt can be used for the effective control of populations of several dipteran disease vectors. The aim of this review is to provide an overview of the use of $B t$ for crop protection and to deal with the problem of the emergence of insects resistant to this biopesticide. We will begin by presenting various aspects of the biology of this entomopathogenic micro-organism, focusing on the diversity and mode of action of the insecticidal toxins it produces. We will then present several examples of utilization of commercially available $B t$ products used as sprays or as transgenic crops. Finally, we will describe the principal strategy for the use of $B t$ transgenic plants, developed so as to prevent or delay the emergence of resistance in target insect populations.
\end{abstract}

Bacillus thuringiensis / biopesticide / $\delta$-endotoxin / transgenic plants / resistance management / Cry protein

\section{INTRODUCTION}

The use of entomopathogenic micro-organisms for regulating the populations of insect pests was first proposed at the end of the 19th Century by several pioneering scientists, including Louis Pasteur. A large range of micro-organisms such as bacteria, viruses, fungi and protozoans have since been identified as potential candidates for use in biocontrol strategies against insect pests (Riba and Silvy, 1989). Given the undesirable effects of chemical insecticides and public health problems in tropical countries, these biopesticides - which also present the advantage of having only a minor impact on the environment - have come to occupy a stable, although modest position in the insecticide market. The biopesticide market currently accounts for $2 \%$ of the worldwide crop protection market of about 600 million US dollars, with about $90 \%$ of all biopesticide sales involving products based on Bacillus thuringiensis $(B t)$. There are many reasons for this success: the larvicidal activity of $B t$ is rapid but sustained, $B t$ can be applied with standard equipment and its effects on beneficial insects and non-target organisms are negligible. The advantages of $B t$ have not escaped biotech companies, which began introducing $B t$ genes into many crop plants, including cotton and maize, at the end of the 1980s. The insertion of these genes leads to the production of $B t$ toxins in various tissues, protecting the plant against attacks by several highly damaging pests. How-

*Corresponding author: vincent.sanchis@jouy.inra.fr ever, the use of these transgenic crops remains highly controversial in Europe, but is increasing year after year over the world. Hence, the cultivation of transgenic plants expressing genetically modified $B t$ genes has increased considerably in recent years, reaching more than 32 million hectares worldwide in 2006 (James, 2006). This expansion of the area under $B t$ crops has greatly increased the selection pressure exerted on the pests targeted by the toxins, increasing the risk that mutations conferring greater tolerance to $B t$ toxins will be selected. An increase in the frequency of these mutations in pest populations would decrease the efficacy of these genetically modified plants, perhaps even rendering them ineffective. In the face of this risk of resistance, a resistance management strategy specifically adapted to transgenic plants was proposed and has been operational in the US since 2000. It is difficult to estimate the true efficacy of this strategy but, in 2006, six years after its introduction, no increase in resistance level to $B t$ crops has yet been recorded.

\section{THE BACTERIUM}

Bacillus thuringiensis comprises bacteria from the Bacillus cereus sensu lato group capable of synthesizing during sporulation a protein crystal consisting of $\delta$-endotoxins with insecticidal activity. This crystalline inclusion may make up about $25 \%$ of the dry weight of the bacterium (Fig. 1). Bt was first isolated in 1901, from infected silk worms, Bombyx mori (L.), 


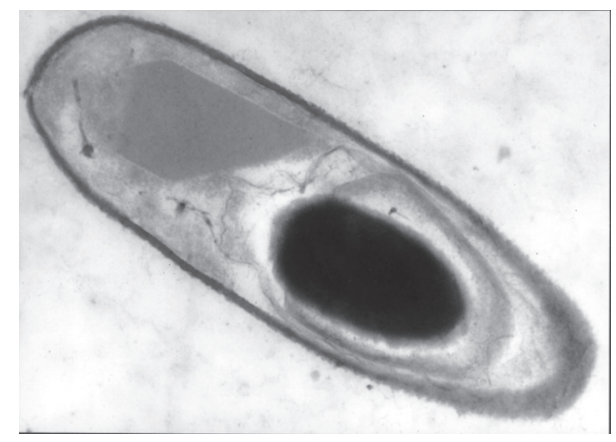

Figure 1. Transmission electron micrograph of a longitudinal section of Bacillus thuringiensis towards the end of sporulation, showing the spore (black ovoid structure) and the protein crystal with insecticidal properties (bipyramidal inclusion). Photo: from Institut Pasteur, Station Centrale de Microscopie Électronique.

by the Japanese bacteriologist S. Ishiwata (Ishiwata, 1901). It was subsequently rediscovered in 1911 by the German biologist Berliner, who isolated it from infected chrysalids of the Mediterranean flour moth, Ephestia kuehniella (Zell.), collected from a mill in the province of Thuringe (Berliner, 1915). He called this bacterium Bacillus thuringiensis. Agronomists soon became interested in the entomopathogenic properties of $B t$, because small amounts of preparations of this bacterium were sufficient to kill insect larvae rapidly. The first formulation based on $B t$ was developed in France in 1938, under the name "Sporéine", but the first well-documented industrial procedure for producing a Bt-based product dates from 1959, with the manufacture of "Bactospéine" under the first French patent for a biopesticide formulation. Commercial formulations of $B t$ consist of spore/crystal preparations obtained from cultures in fermentors; the preparations are dried and used in a granulated or wettable powder formulation for use as a spray. $\delta$-endotoxins are highly diverse, resulting in a generally restricted activity spectrum for each individual toxin, and are innocuous to plants, animals and almost all non-target insects (bees, ladybirds and other auxiliary biological control agents) (Marvier et al., 2007). The industrial-scale production of $B t$ is now well controlled and relatively simple, and is competitive in terms of cost, and this obviously contributes to its success.

\section{DIVERSITY OF THE $\delta$-ENDOTOXINS (CRY PROTEINS) OF BACILLUS THURINGIENSIS}

The first gene encoding a $\delta$-endotoxin was entirely sequenced in 1985 (Schnepf et al., 1985). Around 400 cry genes encoding $\delta$-endotoxins have now been sequenced (Crickmore et al., 2005). The various $\delta$-endotoxins have been classified into classes (Cry 1, 2, 3, 4, etc.) on the basis of amino acid sequence similarities. These classes are composed of several subclasses (Cry1A, Cry1B, Cry1C, etc.), which are themselves subdivided into subfamilies or variants (Cry1Aa, Cry1Ab, Cry1Ac, etc.). Current nomenclature for $\delta$ endotoxins includes 51 classes (Cry 1 to Cry 51) and a current list of $\delta$-endotoxins genes can be found on the Internet at http://www.lifesci.sussex.ac.uk/home/Neil_Crickmore/Bt/ holo2.html. The genes of each class are more than $45 \%$ identical to each other. The product of each individual cry gene generally has a restricted spectrum of activity, limited to the larval stages of a small number of species. However, it has not been possible to establish a correlation between the degree of identity of Cry proteins and their spectrum of activity. The Cry1Aa and Cry1Ac proteins are $84 \%$ identical, but only Cry1Aa is toxic to Bombyx mori (L.). Conversely, Cry3Aa and Cry7Aa, which are only $33 \%$ identical, are both active against the Colorado potato beetle, Leptinotarsa decemlineata (Say). Other Cry toxins are not active against insects at all, but are active against other invertebrates. For example, the Cry5 and Cry6 protein classes are active against nematodes. More recently, binary toxins from Bt designated as Cry34Ab1/Cry35Ab1, active against various Coleopteran insect pests of the Chrysomelidae family have also been characterized. They have been assigned a Cry designation, although they have little homology to the other members of the Cry toxin family. The Cry34A and Cry35A are 14-kDa and 44-kDa proteins, respectively, that function as binary toxins showing activity on the western corn rootworm, Diabrotica virgifera virgifera (LeConte) (Ellis et al., 2002). Dow AgroSciences and Pioneer Hi-Bred have constructed transgenic corn expressing this binary toxin (see Tab. I).

In addition to the $\delta$-endotoxins, other toxins may be produced by various isolates of $B$. thuringiensis. One such toxin class is the Vegetative insecticidal protein (Vip) 3A (Estruch et al., 1996) which has broad toxicity against lepidopteran species. Genetically engineered products expressing Vip3A are also being evaluated in cotton and maize plants. Although it has similar properties to the $\delta$-endotoxins, the Vip3A toxin has not been classified as a $\delta$-endotoxin.

\section{SPECIFICITY, STRUCTURE AND MODE OF ACTION OF $\delta$-ENDOTOXINS}

$\delta$-endotoxins act on the cells of the intestinal epithelium of susceptible insects. Following ingestion, the crystals first dissolve in the intestinal tract, facilitated by the reducing conditions and high $\mathrm{pH}$ typical of the insect gut. $\delta$-endotoxins are in fact protoxins of around $135 \mathrm{kDa}$. They are cleaved in vivo by the digestive proteases of the host to generate mature toxins of about $65 \mathrm{kDa}$ (the amino-terminal part of the protoxin). The peptide sequence of the carboxy-terminal part of the molecule that is dispensable for toxicity contains almost all the cysteine residues of the protein and is believed to play a role in the formation of disulfide bridges linking $\delta$-endotoxins in the crystal. The high $\mathrm{pH}$ and reducing conditions prevailing in the guts of most susceptible insects therefore seem to be necessary for the destabilization of ionic bonding and the disruption of intermolecular disulfide bridges. Some 65 to $75 \mathrm{kDa}$ Cry proteins lacking the carboxy-terminal extension found in the long protoxins, and that is eliminated by proteolysis, have also been identified, e.g. the Cry $2 \mathrm{~A}$ and Cry $3 \mathrm{~A}$ proteins. Following their solubilization and activation, $\delta$-endotoxins bind to receptors on the surface of intestinal epithelial cells in susceptible 
Table I. Examples of genetically engineered Bt plants approved for sale.

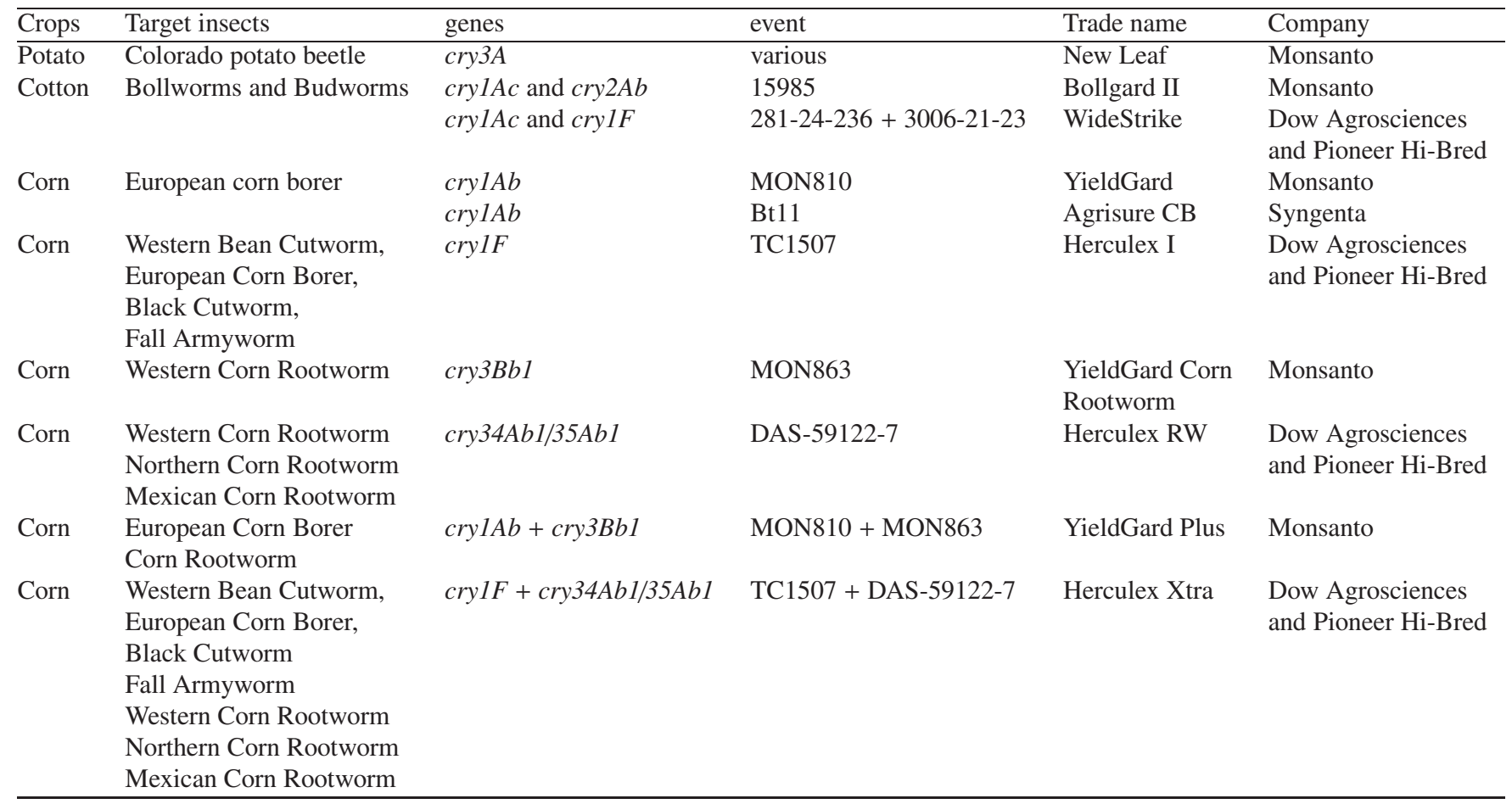

insects (Van Rie et al., 1990). The first three-dimensional structure of an activated $\delta$-endotoxin, the Cry3Aa toxin, was determined in 1991 ( $\mathrm{Li}$ et al., 1991); the toxin is composed of three distinct domains (Fig. 2) and its structure suggests that it is able to create pores in epithelial membranes.

The first domain consists of seven hydrophobic alpha helices, at least five of which have structural characteristics (length, distribution of polar residues) enabling them to insert into the cytoplasmic membrane. The second domain consists of three groups of anti-parallel beta-strands, terminating in loops at the apex of this domain (Fig. 2). Various studies in which one or several of the amino acids present in these loops were modified have shown that these amino acids are involved in the interaction between the toxin and its receptor in insects (Smedley and Ellar, 1996). The third domain has a beta-sandwich structure and may be responsible for the stability of $\delta$-endotoxins in the insect gut after activation. However, several studies have suggested that domain 3 may also be involved in the specific binding of the toxin to its receptors (De Maagd et al., 2000, 2003). The specific receptors of some of the proteins of the $\delta$-endotoxin family have been identified and shown to be membrane aminopeptidases (Knight et al., 1994) or proteins of the cadherin family (Vadlamudi et al., 1995). Currently, 38 different aminopeptidases have been reported for 12 different lepidopterans (for a review, see Piggot and Ellar, 2007). Bravo et al. (2004) elucidated the stages involved in the binding of Cry $1 \mathrm{Ab}$ to its receptors and the ensuing interactions between toxin and receptor. Two cadherin-like receptors and an aminopeptidase $\mathrm{N}$ act sequentially. The monomeric form of Cry1 Ab seems to bind preferentially to cadherin-like recep-

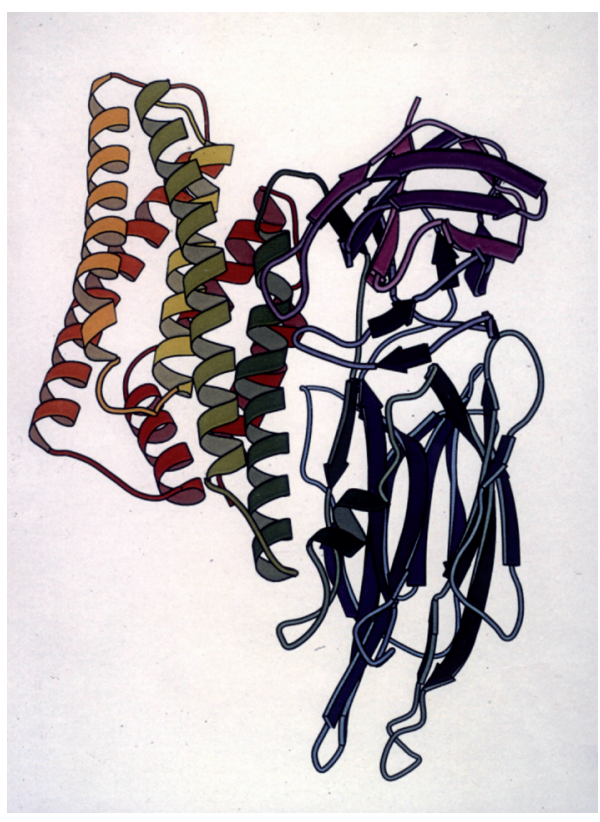

Figure 2. Three-dimensional structure of activated Cry3Aa toxin. Schematic diagram showing the three domains of the protein. (Image courtesy of D.J. Ellar, University of Cambridge, United Kingdom).

tors and this binding is followed by proteolysis, resulting in a conformational change facilitating toxin oligomerization. The resulting oligomers have a higher affinity for the aminopeptidase N-type receptor, and probably for other glycolipid or 
sugar molecules of the $\mathrm{N}$-acetylgalactosamine type. The phase following the binding of the toxin to its receptor, and the possible contribution of the receptor to toxicity, have not been completely elucidated. However, it is widely believed that the toxin acts by osmocolloidal cytolysis, following the formation of pores in intestinal cells (Knowles, 1994). In other words, pore formation may disturb ion exchange, leading to cell lysis. A mechanism involving an intracellular signaling phenomenon following the binding of the toxin to a cadherin-like receptor, leading to apoptosis, has also been proposed (Zhang et al., 2006). However, these two mechanisms (osmotic shock due to the formation of pores and/or apoptosis) are not necessarily exclusive. Intoxication manifests itself physiologically as almost immediate paralysis of the digestive tract, preventing food intake (Angus, 1954). This paralysis is followed by destruction of the intestinal epithelium. This results in communication between the haemolymph and the intestinal cavity, leading to a decrease in intestinal $\mathrm{pH}$, in turn allowing the spores ingested with the crystal to germinate and the resulting vegetative cells to multiply in the insect cadaver.

\section{B. THURINGIENSIS AND ITS USES IN CROP PROTECTION AND DISEASE VECTOR CONTROL}

$B t$ is remarkably non-toxic to humans and to a large extent non-target fauna and is easy to use, making it a popular alternative to chemical treatments for crop protection. Most of the $B t$ formulations are used to control many common leaf-feeding caterpillars, including caterpillar pests on vegetables, the larvae of the gypsy moth, Lymantria dispar (L.), in forests, and European corn borer (ECB) larvae, Ostrinia nubilalis (Hbn.), in corn fields. Despite the immense diversity of the strains containing different cry toxin genes only 2 subspecies of $B t$ have been developed into sprayable products (kurstaki and aizawaii) to control lepidopteran pests. The most common trade names for these commercial products include Dipel ${ }^{\circledR}$, Javelin ${ }^{\circledR}$, Thuricide ${ }^{\circledR}$, Worm Attack ${ }^{\circledR}$, Caterpillar Killer ${ }^{\circledR}$ and Bactospeine ${ }^{\circledR}$, but many small companies sell similar products under a variety of trade names. Similarly, one strain belonging to the subspecies morrisoni (known as tenebrionis) was developed as a commercially successful product against $L$. decemlineata. The discovery in 1977 of the Bt $\mathrm{H}-14$ strain - known as Bacillus thuringiensis var. israelensis $(B t i)$ - which is highly toxic to mosquito and blackfly larvae (both vectors of tropical diseases, such as malaria, onchocercosis and dengue fever) has led to $B t$ being also widely used in the urban control of mosquitoes and the peridomestic and rural control of blackfly. Many commercial $B t$ products that utilize Bti are also available; among them Vectobac ${ }^{\circledR}$, Teknar ${ }^{\circledR}$, Bactimos ${ }^{\circledR}$ and Skeetal ${ }^{\circledR}$. The World Health Organization (WHO), through the Onchocercosis Control Program (OCP), has been an important promoter of the use of $B t i$ against dipteran larvae. Bt-based formulations have been used intensively, since the 1980s, on the rivers of West Africa, with the aim of combating the blackfly species complex, which is responsible for transmitting Onchocerca volvulus (Leuck.), a microfilarial parasite causing river blindness. In this vector control strategy, the cycle of transmission is broken by eliminating blackfly larvae by the aerial coverage of fast-flowing rivers with insecticides in 11 countries in West Africa; this required the weekly treatment of up to $50000 \mathrm{~km}$ of river irrigating 1.3 million $\mathrm{km}^{2}$. In order to assess the environmental impact of such treatments a network of sampling stations was established. Despite the increase in $B t$ use, the ecological assessment by hydrobiologists is reassuring, in that no irreversible effect of the insecticides used on aquatic ecosystems has been detected (Levêque et al., 1988; Calamari et al., 1998). In France, l'Entente Interdépartementale pour la Démoustication (EID) - an agreement between administrative districts concerning mosquito control for both economic reasons and to encourage tourism - has led to a pest control program covering several départements (French administrative units) and regions (the Atlantic coast, Rhône, Isère, Savoie, the Western Pyrenees, the Mediterranean, etc.). For example, a LIFE-Environment project based on the use of $B t$ was adopted by the Mediterranean EID in 1999 (http://www.eid-med.org). This organization is responsible for mosquito control measures along the whole of the Languedoc-Roussillon coast. Similarly, in Germany, a hundred towns and villages along the Rhine Valley have united to form an organization responsible for mosquito eradication: the Kommunale Aktionsgemeinshaft zur Bekämpfung der Schnakenplage Ludwigshafen (KABS). The KABS covers more than $300 \mathrm{~km}$ of river and about $600 \mathrm{~km}^{2}$ of flood-prone land. Between 1988 and 1999, about $90 \%$ of the 170000 hectares of potential larval breeding sites were treated with preparations based on $B t$ (Becker, 2000).

Nevertheless, despite the increasing use of biological insecticides for the control of dipteran vectors of tropical diseases, $B t$ products remain most widely used in agriculture, which still accounts for more than $60 \%$ of the market for these bioinsecticides. The distribution of sales in this market remains highly uneven: geographically, $55 \%$ of all sales are in North America and only 8\% in Europe. In terms of production systems, forests and fruit and vegetable crops account for $80 \%$ of $B t$ bioinsecticide use. In the future, the increased competition from transgenic plants and new chemistries may have an impact on sprayable $B t$ products in vegetable, forest and tree fruit markets. However, new market opportunities for $B t$ may arise as consumers seek alternatives to products that have been sprayed with conventional chemical insecticides. Indeed, given the regulations concerning the use of insecticides innocuous to mammals and non-target animals in force for certain types of crops, these products are, in some cases, the only available option in cases of infestation. In 2001, in the US, more than 20000 ha of brassica and tomato crops (corresponding to $60 \%$ of the total area under brassicas and $40 \%$ of the area under tomato), together with 40000 ha of vines (10\% of the entire area under vines), 35000 ha of almond orchards and 23000 ha of apple orchards (18\% and 13\% of the area under these trees) were treated with $B t$ (Walker et al., 2003). In forests, almost 3.5 million hectares of forest were treated with various $B t$ formulations between 1980 and 1998, to combat the spruce budworm, Choristoneura fumiferana (Clem.) 


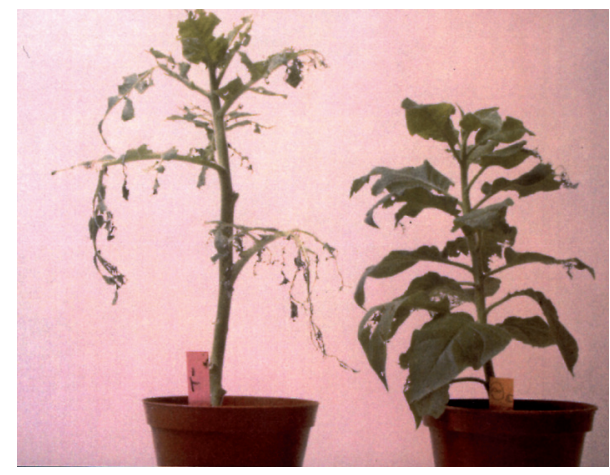

Figure 3. Transgenic tobacco transformed with the cry1C gene. On the left, an untransformed control plant. On the right, tobacco transformed with the crylC gene, modified for expression in plants. In both cases, 40 Spodoptera littoralis second instars were placed on the leaves. The photograph shows the damage after 72 hours (photograph courtesy of J. Tourneur, INRA).

(521000 ha), the western spruce budworm, Choristoneura occidentalis (Free.) (547000 ha) and L. dispar (2435000 ha). In Canada, between 1980 and 1999, almost 6 million hectares of forest were treated by aerial spraying with products based on $\mathrm{Bt}$. It is also estimated that 1.8 million hectares of forest in Europe (corresponding to about $26 \%$ of the area treated) were treated with Bt-based products between 1990 and 1998 (Van Frankenhuyzen, 2000).

\section{THE EXPRESSION OF CRY GENES IN PLANTS}

Several teams working in the domain of plant transgenesis decided to make use of the insecticidal potential of $B t$ to generate genetically modified plants expressing $\delta$-endotoxin genes (Fig. 3). A first decisive step in this direction was taken in 1987, with the production of tobacco plants transformed with the $B t$ crylAb gene (Vaeck et al., 1987) a gene whose product is active against the European corn borer, one of the main pest attacking maize in the US and Europe. This insect, due to the way it attacks plants, is particularly difficult to control with a standard insecticide treatment. The young ECB caterpillars burrow into the apical bud and then penetrate into the interior of the stem, creating a network of holes in the soft tissue. Thus, the insect rapidly finds shelter from classical insecticides and the damage it causes is not immediately apparent. A promising approach to control this type of pests was to create genetically engineered maize plants, expressing a cry $B t$ transgene in the tissues that are prone to the insect attack, in order to neutralize it before causing major damage.

The development of new methods of plant transformation, based on electroporation or particle bombardment, subsequently made it possible to transfer Bt cry genes into most plants, including monocots such as maize. However, despite the use of strong promoters, toxin production in plants was initially too weak for effective agricultural use (Koziel et al., 1993). Unlike plant genes, $B t$ genes have a high $\mathrm{A}+\mathrm{T}$ content $(66 \%)$, which is a suboptimal codon usage for plants, and potentially leads to missplicing or premature termination of transcription (De la Riva and Adang, 1996). The coding sequence of cry genes has been modified (without modifying the encoded peptide sequence) to ensure optimal codon usage for plants, and this allowed toxin production in plants to be increased by two orders of magnitude (Perlak et al., 1991). This strategy has been successfully used in many plants: cotton, rice and maize have been transformed with modified cryl genes and potato has been transformed with a modified $\operatorname{cry} 3 \mathrm{~A}$ gene (Tab. I).

$B t$ potatoes were first developed and sold by Monsanto in the United States in 1994 under the NewLeaf trademark for control of the Colorado potato beetle (Perlak et al., 1993). The use of NewLeaf potatoes led to a significant reduction in pesticide use and cost savings for growers. However, they were only considered as a marginal niche market by Monsanto and sales were discontinued in 2001. In 1996, authorization was obtained for the cultivation and sale in the US of transgenic plants expressing certain lepidopteran active cry genes (reviewed in Sanchis, 2000). Today, $B t$ maize and $B t$ cotton are cultivated on a large scale, throughout the world. In 2006, these transgenic crops covered an area of 32.1 million ha (James, 2006). Insect-resistant crops covered 19 million ha (19\% of the area under genetically modified organisms (GMOs)) and crops with a combination of transgenic traits (insect resistance and herbicide tolerance) covered 13.1 million ha (13\% of the area under GMOs) (James, 2006). Bt cotton adoption has resulted in a significant decrease in the use of insecticides in all cases studied (25\% of all insecticide used in agriculture worldwide is for cotton cultivation). By contrast, $B t$ maize adoption has induced only a little decrease in insecticide use, since the pests $B t$ maize is designed to resist were not usually controlled by insecticide applications (James, 2006).

In 2006 Bt cotton was grown in nine countries: Australia, Argentina, China, Colombia, India, Indonesia, Mexico, South Africa and the United States. Bt maize was grown in fourteen countries: Argentina, Canada, Colombia, the Czech Republic, France, Germany, Honduras, the Philippines, Portugal, Slovakia, South Africa, Spain, Uruguay and the United States (James, 2006).

Bt cotton was first adopted in India as hybrids in 2002. In this year India grew approximately 50000 hectares of officially approved $B t$ cotton hybrids. Three years later, in 2005, the area planted to $B t$ cotton in India reached 1.3 million hectares, and in 2006, 3.8 million hectares (60\%) of the 6.3 million hectares of hybrid cotton in India (which represents $70 \%$ of all the cotton area in India) was $B t$ cotton. However, in 2007, it has been reported that in southern Punjab farmers had to spray pesticides worth over $\$ 120$ millions to save their cotton crop from the mealy bug (a new insect pest on cotton considered deadlier than the American bollworm) that is now threatening the cotton crop in Punjab and elsewhere in the region (Singh-Ashk, 2007). At least 25 percent of the crop has already been destroyed. This points out that we should never forget that introducing new technologies can also give rise to a new set of problems, including pest shifts.

In China, sixty-four improved cotton varieties have been approved for environmental release. Of these, many varieties 
have been examined by the national government and confirmed as pest-resistant and high-yielding. These have been put into production in 12 provinces and $B t$ cotton is the most extensively grown transgenic crop in China today. In 2005, China grew 3.3 million hectares of $B t$ cotton, occupying about $66 \%$ of the national cotton area (Huang et al., 2007). However, like in India, $B t$ cotton is clearly not as profitable as it is in the US. The problem in China is not due to the bollworm developing resistance to $B t$ cotton but, as happened in India, because of secondary pests that are not targeted by the $B t$ cotton and which previously were controlled by the broadspectrum pesticides used to control bollworms (Wang et al., 2006). This problem could be circumvented, since a particularity of China is the availability of new $B t$ cotton varieties developed by the public research group. A series of transgenic $B t$ rice lines transformed with modified $c r y l A, c r y l A b$ or $c r y l A c$ genes have also been approved for large-scale pre-productive trials and are now in the process of rigorous biosafety assessment which is the last step before commercialization (Huang et al., 2007).

\section{THE REGULATIONS CONCERNING GMOS IN EUROPE AND IN FRANCE}

In Europe, the authorization procedure for the voluntary dissemination and sale of genetically modified organisms (GMOs) is fixed by European directive 2001/18/CE, dating from March 12th 2001. A moratorium was nonetheless imposed, at the instigation of five Member States, including France, at the Council of Environment Ministers in June 1999, in the absence of precise and reliable mechanisms for tracing and labeling GMOs. This moratorium was lifted in 2003, following the adoption of communitywide regulations for GMO traceability and labeling. However, only six countries within the European Union currently authorize the sale of $B t$ maize (Spain, Germany, Portugal, France, the Czech Republic and Slovakia). Portugal and France lifted moratoria of four and five years, respectively, on the cultivation of $B t$ maize in 2005, whereas the Czech Republic authorized the planting of $B t$ maize for the first time in 2005. In 2007, according to GMO Compass (http://www.gmo-compass.org/eng/agri_biotechnology/ gmo_planting/191.eu_growing_area.html), 75000,20000 , 5000,3000 and 2500 ha of $B t$ maize were sown and harvested in Spain, France, the Czech Republic, Portugal and Germany. In France, a draft law relating to GMOs was approved during its first reading at the Senate on March 23rd 2006. This law transposes the European directives 90/219/CEE (relating to the restricted use of GMOs) and 2001/18/CE into French law. Nonetheless, the French government delayed the presentation of this law on GMOs to its parliament until after the presidential elections held in May 2007. Actually, this law will be discussed early 2008 after the French "Grenelle de l'Environnement" ecological talks. Unveiling the country's new environmental policy. French president Sarkozy proposed a temporary freeze on the planting of genetically modified crops in France after the government received the results of an evaluation by a new authority on GMOs early in 2008. Nevertheless, GMOs with EU-wide authorization obtained before 1999 can be sold in France without additional national authorization.

\section{STATUS OF GMO MAIZE IN FRANCE IN NOVEMBER 2006}

The European catalog of varieties currently includes 35 GMO varieties, including:

- 1 Bt11 maize variety, highly tolerant to the ECB and glufosinate, from Syngenta.

- 20 Mon810 maize lines, protected against the ECB, from Monsanto.

However, in France, the authorization to cultivate and to disseminate seeds of GMO varieties authorized for sale by the EU requires their listing in the national catalog of species and varieties. This listing depends on a decision by the Minister of Agriculture, based on the advice of a consultative committee, the Permanent Technical Selection Committee (CTPS, Comité Technique Permanent de la Sélection). Varieties are listed in the catalog if they pass DUS tests (distinctness, uniformity and stability tests) and VCU (value for cultivation and use) tests. In France, GEVES (le Groupe d'Étude et de Contrôle des Variétés et des Semences; the Variety and Seed Study and Control Group) is responsible for carrying out these tests for the CTPS, making it possible to determine whether the proposed varieties merit listing in the official catalog. Varieties derived from the Mon810 lineage have been authorized in France and are listed in the national catalog. By contrast, authorization has not yet been sought for the Bt11 variety, which is therefore not listed in the national catalog.

The sale of genetically modified maize seeds may be authorized for a period of up to 10 years. This authorization is accompanied by monitoring (biovigilance), the use of seeds for the evaluation of possible effects of the transgenic crop on the environment (emergence of moths resistant to $B t$ toxin, effects on populations of non-target insects and on soil bacteria) and monitoring of animal consumption of the maize produced (changes in the digestive flora). A biovigilance committee was set up for this purpose in March 1998. This committee includes scientific experts and lay representatives.

\section{RESISTANCE TO THE $\delta$-ENDOTOXINS OF BT}

The scientific community considers the emergence of populations of pests, resistant to the toxins produced by different varieties of $B t$ crops, to be probable. The resulting resistant larvae would be able to eat the foliage of these transgenic plants, which would therefore become ineffective at controlling the damage caused by this pest. This concern is based on past experience in the domain of crop protection. We have long been aware of the development of resistance to chemical pesticides in insect pests. Fifty years of theoretical and practical studies 
have shown that an increase in the number of resistant individuals over time is almost inevitable in populations exposed to chemical treatments. Certain populations of aphids, such as the cotton aphid, Aphis gossypii (Glov.), have become resistant to almost all the major classes of insecticide known. Thus, all insecticides have a high probability of becoming ineffective. There is no theoretical reason why this should not also be true for $B t$ toxins. As for antibiotics, herbicides and fungicides, the generalization of resistance to $B t$ toxins is likely to be a particularly severe problem whilst the number of toxins potentially useful against crop pests remains small.

\section{THE HIGH DOSE-REFUGE STRATEGY}

The "high dose-refuge" (HDR) strategy for managing resistance to $B t$ plants has been implemented in several countries after it was set, for the first time, in the United States. This method is one of the best-known strategies for slowing the development of resistance in pest populations. It involves growing plots of $B t$ crops producing large amounts of toxin alongside non- $B t$ crops' plots (referred to as refuge zones), in which the larvae of target insects are not exposed to the toxin; these larvae therefore constitute a reservoir of susceptible individuals (Alstad and Andow, 1995). An understanding of genetics is required to comprehend the functioning of the HDR strategy. Resistance is a consequence of genetic mutations. We can therefore distinguish between the wild-type form of the gene, known as the susceptibility (S) allele, and the mutated form, known as the resistance $(\mathrm{R})$ allele. Insects with two susceptibility alleles are SS homozygotes and are susceptible. Insects with one copy of each allele are RS heterozygotes and insects with two copies of the resistance allele are RR homozygotes (and are consequently resistant). The HDR strategy is based on the observation that $\mathrm{Bt}$ resistance is rarely dominant (Bourguet et al., 2000; Tabashnik et al., 2003) and, in some pests like the ECB, initially at low frequency (Bourguet et al., 2003). If the $B t$ plants produce sufficiently large amounts of toxin one might therefore expect these plants to kill all SS homozygotes and all RS heterozygotes. If this is the case, only a few RR homozygotes can develop and emerge from the $B t$ crop plots. Provided the high-dose and refuge plots are appropriately spaced, RR individuals are likely to mate with SS individuals from the refuge zones (but see Dalecky et al., 2006). The offspring of these crosses will consist mostly of susceptible RS heterozygotes unable to develop on the $B t$ plants in the next generation, thereby decreasing the frequency of the resistance alleles (Fig. 4). Note that these alleles might eventually remain at low frequency if they are associated with a fitness cost - i.e. if adaptation RR and/or RS individuals have a lower fitness than $\mathrm{SS}$ in the absence of the selective pressure; in this case, the $B t$ toxin (e.g. Higginson et al., 2005).

The amount, and location size of refuges that are necessary will differ depending on the mobility and ecology of the insect and whether or not the refuge is sprayed with any chemical control. This approach also assumes that mating will be random between insects living in the refuges and those in the crop being sprayed or the genetically modified crop. This strategy is currently used in commercial production in several countries.

\section{EVOLUTION OF RESISTANCE IN NATURAL POPULATIONS}

The first case of resistance to $B t$ toxins selected in the laboratory was in a population of Indian meal moths, Plodia interpunctella (Hbn.) (McGaughey, 1985). Strains resistant to one or several $B t$ toxins have since been selected in about 10 insect species (Tabashnik et al., 1994, 2003). However, the situation in the field remains very different. To date, the only natural populations that have really developed resistance following $B t$-based treatments have been populations of diamondback month, Plutella xylostella (L.). The first resistant lines of this lepidopteran were detected in populations sampled on watercress in Hawaii. One of these populations had been subjected to 15 treatments with $B t$-based biopesticides over the course of 18 months and the other had been subjected to between 50 and 400 such treatments between 1982 and 1989.

The use of transgenic plants has greatly increased the selection pressure on target pest populations. However, the several thousand ha of $B t$ maize planted in France during the first field trials and the agricultural production of such crops by a few producers until the years 2006-2007 have had much less impact than the 3 million ha of conventional maize planted each year, to the extent that the selection pressure exerted on ECB populations may be considered negligible. As expected, susceptibility monitoring over the last five years, carried out by the Plant Protection Service (SPV; Services de la Protection des Végétaux) at the request of the Biovigilance Committee, has found no evidence for the evolution of resistance in French ECB populations. More surprisingly, no resistance problem has been detected among ECB populations in North America (Alves et al., 2006; Stodola et al., 2006), where Bt maize crops have been grown since 1996. Similarly, the monitoring of ECB populations in Spain - the only European country in which Bt crops have been planted over large areas - has revealed no change in susceptibility more than five years after these crops were first introduced (Farinós et al., 2004). Nevertheless, several ECB strains with a lower susceptibility to the principal $B t$ toxins produced by $B t$ maize varieties have been selected in the laboratory (Chaufaux et al., 2001; Farinós et al., 2004; Alves et al., 2006). The level of resistance of these strains resistance factor of 10 to 1000 - is, however, too low to ensure the survival of larvae on the foliage of $B t$ maize plants, particularly on the foliage of varieties generated by transformation events Bt11 and Mon810, in which large amounts of toxin are produced. Finally, estimations made jointly in France and the USA suggest that the frequency of resistance alleles in natural ECB populations is sufficiently low to allow a sustainable management of resistance (Bourguet et al., 2003; Stodola et al., 2006).

Without going into detail, there is limited evolution of resistance to $B t$ cotton in populations of target pest insects feeding on this crop (Tabashnik et al., 2005). 


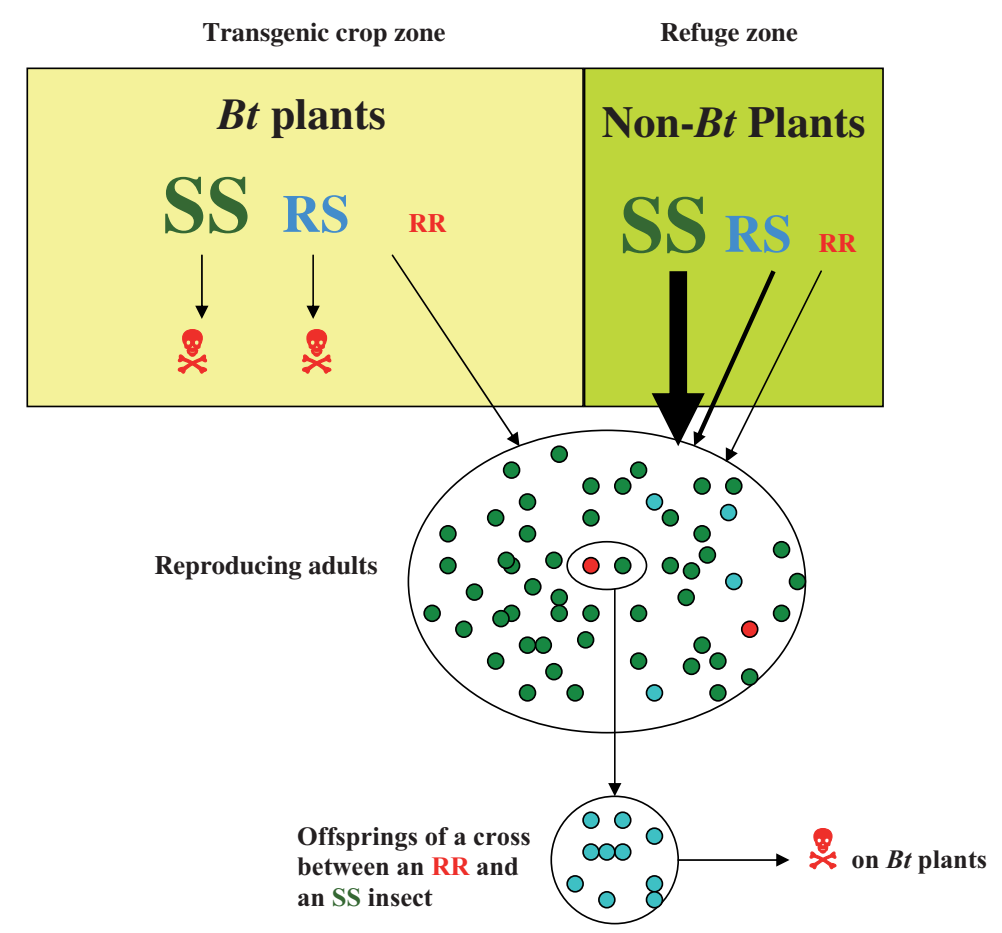

Figure 4. Schematic representation of the "high dose-refuge" (HDR) strategy. The success of the HDR strategy depends on resistance being a rare and recessive trait and the genetically modified plants producing a dose of toxin sufficient to kill all homozygous susceptible individuals (SS-green) and all heterozygous individuals with for both resistance and susceptibility alleles (RS-blue).

There are several possible reasons for the lack of emergence of resistance to $B t$ plants in target pest populations. The first is that the alleles conferring such resistance were initially before the introduction of $B t$ plants - present at such a low frequency that, despite possible increases over the last decade, these alleles remain too rare for detection in the field or selection in the laboratory of resistant individuals. Alternatively, the principal areas in which $B t$ cotton and $B t$ maize crops have been planted on a large scale over the last few years - the US and Canada, in particular - have been managed using the HDR system. The presence of plots of conventional crops not producing toxins, acting as a refuge, may have significantly maintained resistance at a low level. A third possible reason is that the use of $B t$ crops remains limited. For example, over the entire American Corn Belt, $B t$ maize has never covered more than $30 \%$ of the area under maize. Even in the regions most affected by ECB damage, $B t$ crops rarely cover more than $70 \%$ to $30 \%$ of the area under maize. The cultivation of conventional maize varieties by many producers decreases the selection pressure on ECB populations, by providing large natural refuge zones free of $B t$ toxins. It is also possible that the cost of resistance - the decrease in the fitness of resistant individuals compared to susceptible individuals in the absence of $B t$ toxin - is sufficiently high for there to be selection against these alleles in the absence of the toxin. These four possible explanations are, of course, not exclusive. There is reason to believe that all four of these factors have contributed to the non-emergence (for ECB) or limited evolution (for pests targeted by $B t$ cotton) of resistance during the first 10 years of $B t$ plants' cultivation.

\section{CONCLUSION}

One of the main advantages of microbial control agents is that they can replace, at least in part, some of the most dangerous chemical insecticides. The use of these safer and biodegradable biological control agents also has a number of ecological advantages. One of these advantages results from their high level of selectivity, their infectious or lethal action being limited to a few species. They are therefore often used in organic agriculture, which is becoming increasingly popular with consumers. Many studies have also highlighted the benefits of exploiting $B t$ for the protection of crops and forests. Progress in molecular genetics has also made it possible to use Bt cry genes as a genetic resource for transgenesis and for the construction of transgenic plants resistant to insects. Bt maize and $B t$ cotton, which constitutively produce $\delta$-endotoxins, are an effective means of controlling their pests - especially the "borers" due to their "endophytic" habits - greatly increasing productivity. However, in some cases, secondary pests that are not killed by the $B t$ toxins produced by the current transgenic varieties of these two crops might significantly decrease the value of this technology, as recently shown in China and India. The extension of pesticide formulations containing $B t$ will depend essentially on our capacity to improve the performance of the products used: activity levels, activity spectrum, quality and stability of formulations, and persistence in the field. The emergence of resistant insects is a problem that both $B t$ sprays and plant products are likely to face in the future. This phenomenon has already been observed in the laboratory, and is likely to become much more acute in natural 
conditions if $B t$ use in agriculture and for human health applications spreads, or in cases of the non-rational use of largescale transgenic crops expressing cry genes. For this reason, many research programs have been launched to anticipate the risk of resistant populations emerging and to design or refine strategies - such as the HDR strategy - for slowing and/or preventing the emergence of resistance. Second-generation transgenic plants are currently being developed. In particular, it is planned to generate plants expressing at least two cry genes encoding toxins recognizing different receptors. Approaches of this type should help to slow the emergence of resistance in insects. However, more detailed studies of the mode of action of $\delta$-endotoxins and of the mechanisms inducing resistance to biological insecticides are also required. An understanding of the mechanisms and genes associated with resistance, and thus of ways to control them, is essential for the future rational use of bioinsecticides and transgenic plants based on $B t$.

\section{REFERENCES}

Alstad D.N., Andow D.A. (1995) Managing the Evolution of Insect Resistance to Transgenic Plants, Science 268, 1894-1896.

Alves A.P., Spencer T.A., Tabashnik B.E., Siegfried B.D. (2006) Inheritance of resistance to the Cry1 Ab Bacillus thuringiensis toxin in Ostrinia nubilalis (Lepidoptera: Crambidae), J. Econ. Entomol. 99, 494-501.

Angus T.A. (1954) A Bacterial toxin paralysing silkworm larvae, Nature $173,54-56$.

Becker N. (2000) Bacterial control of vector-mosquitoes and black flies, in: Charles J.F., Delécluse A., Nielsen-Leroux C. (Eds.), Entomopathogenic Bacteria: From Laboratory to Field Application, Kluwer Academic Publishers, Dordrecht, The Netherlands, pp. 383-398.

Berliner E. (1915) Über die Schlaffsucht der Mehlmottenraupe (Ephestia kühniella Zell.) und ihren Erreger Bacillus thuringiensis, n.sp., Z. Angewandte Entomologie 2, 29-56.

Bourguet D., Génissel A., Raymond M. (2000) Insecticide resistance and dominance levels J. Econ. Entomol. 93, 1588-1595.

Bourguet D., Chaufaux J., Seguin M., Buisson C., Hinton L., Stodola T.J., Porter P., Cronholm G., Buschman L.L., Andow D.A. (2003) Frequency of alleles conferring resistance to Bt maize in French and US corn belt populations of the European corn borer, Ostrinia nubilalis, Theor. Appl. Genet. 106, 1225-1233.

Bravo A., Gomez I., Conde J., Munoz-Garay C., Sanchez J., Miranda R., Zhuang M., Gill S.S., Soberon M. (2004) Oligomerization triggers binding of a Bacillus thuringiensis Cry1 Ab pore-formingtoxin to aminopeptidase $\mathrm{N}$ receptor leading to insertion into membrane microdomains, Biochim. Biophys. Acta 1667, 38-46.

Calamari D., Yameogo L., Hougard J.-M., Levêque C. (1998) Environmental assessment of larvicide use in the onchocerciasis programme, Parasitol. Today 14, 485-489.

Chaufaux J., Seguin M., Swanson J.J., Bourguet D., Siegfried B.D. (2001) Chronic exposure of the European corn borer (Lepidoptera: Crambidae) to Cry1 Ab Bacillus thuringiensis toxin, J. Econ. Entomol. 94, 1564-1570.

Crickmore N., Zeigler D.R., Schnepf E., Van Rie J., Lereclus D., Baum J., Bravo A., Dean D.H. (2005) Bacillus thuringiensis Toxin Nomenclature (Homepage), http://www.lifesci.sussex.ac.uk/Home/Neil_Crickmore/Bt/.
Dalecky A., Ponsard S., Bailey R.I., Pélissier C., Bourguet D. (2006) Resistance evolution to $B t$ crops: predispersal mating of European corn borers, PLoS Biology 4, 1048-1057.

De la Riva G., Adang M.J. (1996) Expression of Bacillus thuringiensis $\delta$-endotoxin genes in transgenic plants, Biotecnologia Aplicada 13, 251-260.

Ellis R.T., Stockhoff B.A., Stamp L., Schnepf H.E., Schwab G.E., Knuth M., Russell J., Cardineau G.A., Narva K.E. (2002) Novel Bacillus thuringiensis binary insecticidal crystal proteins active on western corn rootworm, Diabrotica virgifera virgifera LeConte, Appl. Environ. Microbiol. 68, 1137-1145.

Estruch J.J., Warren G.W., Mullins M.A., Nye G.J., Craig J.A., Koziel M.G. (1996) Vip3A, a novel Bacillus thuringiensis vegetative insecticidal protein with a wide spectrum of activities against lepidopteran insects, Proc. Natl. Acad. Sci. (USA) 93, 5389-5394.

Farinós G.P., de la Poza M., Hernández-Crespo P., Ortego F., Castañera P. (2004) Resistance monitoring of field populations of the corn borers Sesamia nonagrioides and Ostrinia nubilalis after 5 years of Bt maize cultivation in Spain, Entomol. Exp. Appl. 110, 23-30.

Higginson D.M., Morin S., Nyboer M.E., Biggs R.W., Tabashnik B.E., Carrière Y. (2005) Evolutionary trade-offs of insect resistance to Bacillus thuringiensis crops: fitness cost affecting paternity, Evolution, 59, 915-920.

Huang D.-F., Zhang J., Song F.-P., Lang Z.-H. (2007) Microbial control and biotechnology research on Bacillus thuringiensis in China, J. Invert. Pathol. 95, 175-180.

Ishiwata S. (1901) On a kind of severe flacherie (sotto disease), Dainihon Sanshi Kaiho 114, 1-5.

James C. (2006) Preview, global status of commercialized transgenic crops, ISAAA Briefs No. 35 (http://www.isaaa.org).

Knight P.J., Crickmore N., Ellar D.J. (1994) The receptor for Bacillus thuringiensis CryIA(c) delta-endotoxin the brush border membrane of the lepidopteran Manduca sexta is aminopeptidase N, Mol. Microbiol. 11, 429-436.

Knowles B.H. (1994) Mechanism of action of Bacillus thuringiensis insecticidal $\delta$-endotoxins, Adv. Insect Physiol. 24, 273-308.

Koziel G.M., Beland G.L., Bowman C., Carozzi N.B., Crenshaw R., Crossland L., Dawson J., Desai N., Hill M., Kadwell S., Launis K., Maddox D., McPherson K., Heghji M., Merlin E., Rhodes R., Warren G., Wright M., Evola S. (1993) Field performance of elite transgenic maize plants expressing an insecticidal protein derived from Bacillus thuringiensis, Biotechnology 11, 194-200.

Levêque C., Fairhust C.P., Abbau K., Pangy D., Curtis M.S., Traoré K. (1988) Onchocerciasis control programme in West Africa: ten years of monitoring fish populations, Chemosphere, 17, 421-440.

Li J., Carroll J., Ellar D.J. (1991) Crystal structure of insecticidal deltaendotoxin from Bacillus thuringiensis at 2.5 A resolution, Nature 353, 815-821.

Maagd R.A. de, Weemen-Hendriks M., Stiekema W., Bosch D. (2000) Bacillus thuringiensis delta-endotoxin Cry1C domain III can function as a specificity determinant for Spodoptera exigua in different, but not all, Cry1-Cry1C hybrids, Appl. Environ. Microbiol. 66, 1559-1563.

Maagd R.A. de, Bravo A., Berry C., Crickmore N., Schnepf H.E. (2003) Structure, diversity, and evolution of protein toxins from sporeforming entomopathogenic bacteria, Annu. Rev. Genet. 37, 409-33.

Marvier M., McCreedy C., Regetz J., Kareiva P. (2007) Meta-analysis of effects of $B t$ cotton and maize on nontarget invertebrates, Science 316, 1475-1477.

McGaughey W.H. (1985) Insect resistance to the biological insecticide Bacillus thuringiensis, Science 229, 193-195.

Perlak F.J., Fuchs R.L., Dean D.A., McPherson S.L., Fishhoff D.A. (1991) Modification of the coding sequences enhances plant expression of insect control protein genes, Proc. Natl. Acad. Sci. (USA) 88, 3324-3328. 
Perlak F.J., Stone T.B., Muskopf Y.M., Petersen L.J., Parker J.B., Mc Pherson S.A., Wyman J., Love S., Reed G., Biever D. (1993) Genetically improved potatoes: protection from damage by Colorado potato beetles, Plant. Mol. Biol. 22, 313-321.

Pigott C., Ellar D.J. (2007) Role of receptors in Bacillus thuringiensis crystal toxin activity, Microbiol. Mol. Biol. Rev. 71, 255-281.

Riba G., Silvy C. (1989) Combattre les ravageurs des cultures enjeux et perspectives, INRA, Paris.

Sanchis V. (2000) Biotechnological improvement of Bacillus thuringiensis for agricultural control of insect pests: benefits and ecological implications, in: Charles J.F., Delécluse A., NielsenLeroux C. (Eds.), Entomopathogenic Bacteria: From Laboratory to Field Application, Kluwer Academic Publishers, Dordrecht, The Netherlands, pp. 441-459.

Schnepf H.E., Wong H.C., Whiteley H.R. (1985) The amino acid sequence of a crystal protein from Bacillus thuringiensis: deduced from the DNA base sequence, J. Biol. Chem. 260, 6264-6272.

Singh-Ashk G.K. (2007) Bt cotton not pest resistant, The times of India, 24 August 2007.

Smedley D.P., Ellar D.J. (1996) Mutagenesis of three surface-exposed loops of a Bacillus thuringiensis insecticidal toxin reveals residues important for toxicity, receptor recognition and possibly membrane insertion, Microbiol. 142, 1617-1624.

Stodola T.J., Andow D.A., Hyden A.R., Hinton J.L., Roark J.J., Buschman L.L., Porter P., Cronholm G.B. (2006) Frequency of resistance to Bacillus thuringiensis toxin Cry1Ab in southern United States Corn Belt population of European corn borer (Lepidoptera: Crambidae), J. Econ. Entomol. 99, 502-507.

Tabashnik B.E. (1994) Evolution of resistance to Bacillus thuringiensis, Ann. Rev. Entomol. 39, 47-79.

Tabashnik B.E., Carrière Y., Dennehy T.J., Morin S., Sisterson M.S., Roush R.T., Shelton A.M., Zhao J.Z. (2003) Insect resistance to transgenic $B t$ crops: lessons from the laboratory and field, J. Econ. Entomol. 96, 1031-1038.

Tabashnik B.E., Dennehy T.J., Carrière Y. (2005) Delayed resistance to transgenic cotton in pink bollworm, Proc. Natl. Acad. Sci. (USA) 102, 15389-15393.

Vadlamudi R.K., Weber E., Ji I., Ji T.H., Bulla Jr. L.A. (1995) Cloning and expression of a receptor for an insecticidal toxin of Bacillus thruingiensis, J. Biol. Chem. 270, 5490-5494.

Vaeck M., Reynaerts A., Höfte H., Jansens S., De Beukeleer M., Dean C., Zabeau M., Van Montagu M., Leemans J. (1987) Transgenic plants protected from insect attack, Nature 327, 33-37.

Van Frankenhuyzen K. (2000) Applications of Bacillus thuringiensis in forestry, in: Charles J.F., Delécluse A., Nielsen-Leroux C. (Eds.), Entomopathogenic Bacteria: From Laboratory to Field Application. Kluwer Academic Publishers, Dordrecht, The Netherlands, pp. 371-382.

Van Rie J., Jansens S., Hofte H., Degheele D., Van Mellaert H. (1990) Receptors on the brush border membrane of the insect midgut as determinants of the specificity of Bacillus thuringiensis deltaendotoxins, Appl. Environ. Microbiol. 56, 1378-1385.

Walker K., Mendelsohn M., Matten S., Alphin M., Ave D. (2003) The role of microbial $B t$ products in US crop protection, in: Metz M. (Ed), Bacillus thuringiensis: a cornerstone of modern agriculture, Food Products Press, Binghamton, USA, pp. 31-51.

Wang G., Zhang J., Song F., Wu J., Feng S., Huang D. (2006) Engineered Bacillus thuringiensis GO33A with broad insecticidal activity against lepidopteran and coleopteran pests, Appl. Microbiol. Biotechnol. 72, 924-30.

Zhang X., Candas M., Griko N., Taussig R., Bulla Jr. L. (2006) A mechanism of cell death involving an adenylyl cyclase/PKA signaling pathway is induced by the Cry $1 \mathrm{Ab}$ toxin of Bacillus thuringiensis, Proc. Natl. Acad. Sci. (USA) 103, 9897-9902. 